\title{
1 Bond of Reinforcing Bars to Steel Fiber Reinforced Concrete
}

3 E. Garcia-Taengua ${ }^{1 *}$, J.R. Martí-Vargas ${ }^{2}$, P. Serna ${ }^{2}$

$4{ }^{1}$ Institute for Resilient Infrastructure, School of Civil Engineering, University of Leeds, 5 England, United Kingdom.

62 ICITECH-Institute of Concrete Science and Technology, Universitat Politècnica de

7 València, Valencia, Spain

8 e-mail addresses: e.garcia-taengua@ @leeds.ac.uk, jrmarti@cst.upv.es,

9 pserna@cst.upv.es

10 *Corresponding author: e.garcia-taengua@ leeds.ac.uk

\section{ABSTRACT}

13 Steel fiber reinforced concrete (SFRC) has been increasingly used during recent years.

14 Regarding bond of rebars to concrete, fibers provide passive confinement and improve bond capacity in terms of bond strength and, more importantly, toughness. An extensive 16 experimental programme has been carried out, and SFRC specimens with embedded 17 rebars have been subjected to the Pull Out Test to obtain the bond stress-slip curves, 18 retaining the bond strength and the area under the curve as measures of the bond 19 capacity of concrete. The following parameters were considered: concrete compressive 20 strength (30-50 MPa), rebar diameter $(8-20 \mathrm{~mm})$, concrete cover (between $30 \mathrm{~mm}$ and 5 times rebar diameter), fiber content (up to $70 \mathrm{~kg} / \mathrm{m}^{3}$ ), and the slenderness and length of the steel fibers used. Predictive equations have been obtained to relate the experimental results to the factors considered, and the trends observed have been analyzed and 24 discussed.

\section{KEYWORDS:}

Bond; Concrete; Fiber; Strength; Toughness. 


\section{INTRODUCTION}

3 Bond of reinforcement to concrete has been studied for different types of concrete and

4 different experimental setups and structural situations. On the other hand, steel fiber 5 reinforced concrete (SFRC) has been increasingly used. This introduction aims at 6 contextualizing this study and justifying its objectives, which are detailed after that.

$8 \quad 1.1$ Bond between Reinforcement and Concrete

10 Bond between reinforcement and concrete is measured as a shear stress, or bond stress, 11 at the interface between the two materials, distributed over the surface of the rebar along 12 the embedded length. Following this definition, bond stress is the ratio between the rate 13 of change in axial force along the rebar and the area of rebar surface over which this 14 change takes place [1]. In addition to this shear stress there are other aspects involved, 15 especially in the case of deformed, ribbed rebars [1-3]. This is illustrated in Figure 1: 16 the tensile load pulling the rebar out of concrete causes reaction forces applied onto the surrounding concrete. As a result of the ribbed geometry, these reactions are oblique and therefore consist of two components: a) a shear component, parallel to the rebar axis, and b) a radial component which affects the surrounding concrete. Therefore, bond implies not only bond stresses but radial stresses as well.

22 Concrete between ribs is subjected to a multiaxial stress state caused by the shear component of bond stresses. This wedging action increases with the axial load pulling the rebar out, which eventually results in concrete crushing between ribs. Radial stresses increase as well, until concrete tensile strength is reached in the concrete surrounding the rebar. As a result, transverse microcracking occurs, with the consequent loss of strain compatibility between rebar and concrete: the rebar progressively slips out of concrete with the development of these microcracks. The initiation and progress of the slippage results in the activation of bond. As long as confinement is sufficient and the cracks do not imply the total failure of concrete surrounding the rebar, bond stresses keep increasing until the ultimate value, known as bond strength, is reached. After this peak, bond stress-slip curves exhibit a softening behavior. 
1 Depending on the confinement conditions, bond failure can occur in two different major

2 modes: pullout failure (when the rebar is pulled out after the shear failure of the rebar-

3 concrete interface), or splitting failure (when the concrete surrounding the rebar

4 undergoes total splitting as a result of the radial stresses). The confining effect of

5 concrete cover is most usually typified by rebar diameter: concrete cover/diameter ratio

6 is the reference parameter. According to the Model Code [4], concrete is considered

7 well confined when this ratio is not less than five, and it must be higher than 2.5 to

8 prevent splitting failures [5,6], although this threshold varies depending on different

9 factors. A detailed analysis of these factors determining the mode of bond failure and

10 the effect that fibers have on the risk of concrete splitting has already been published [7].

12 Confinement affects bond performance in terms of bond strength and bond failure 13 ductility [4] in addition to the mode of bond failure [8,9]. In terms of ductility, 14 increasing the concrete cover has been shown to improve the ductility of bond failure, 15 as bond stress-slip curves become steeper when concrete cover increases [10].

\subsection{Effect of Steel Fibers on Bond between Reinforcement and Concrete}

Steel fibers have been increasingly introduced in concrete production in recent years $[11,12]$. They improve bond between reinforcement and concrete even when they are dosed at low contents [13] as a result of their confining effect and their broadening the range of crack width values within which passive confinement remains active [13-15].

The positive effect of fibers on bond capacity is acknowledged in codes and recommendations for structural concrete but is not always considered in expressions to determine development lengths. Their effect on bond performance is especially noticeable in terms of toughness of bond failure and the ductility of the material $[10,16]$. However, accounting for the enhanced bond capacity of SFRC in order to reduce required anchorage length values is not a straightforward issue. In this sense, several studies have been performed attempting to model the bond phenomenon and anchorage behavior in general [17-24]. 


\section{2. OBJECTIVES}

3 As it has been highlighted in the introduction, a number of variables are involved in

4 terms of bond of reinforcing bars to SFRC, and there was a need to study all of them

5 together in order to quantify their importance, detect potential synergies between them

6 and non-linear trends. This research aimed at studying bond capacity of SFRC from a

7 multivariate perspective. The main objectives were:

- To study different parameters characterizing the toughness of bond failure under the conditions of the Pull Out Test (POT), and their relation with bond strength.

- To study the effect that steel fiber content, fiber length and slenderness, concrete

\section{EXPERIMENTAL INVESTIGATION}

\subsection{Definition of variables and experimental programme}

The following factors were considered: concrete compressive strength $\left(\mathrm{f}_{\mathrm{c}}\right)$, rebar diameter $(D)$, concrete cover $(C)$, steel fiber content $\left(C_{f}\right)$, fiber slenderness $\left(\lambda_{f}\right)$ and fiber length $\left(l_{\mathrm{f}}\right)$. The values considered for each of these factors are summarized in Table 1.

Three different groups of concrete mixes were considered, providing compressive strength values between 30 and $50 \mathrm{MPa}$. They are referred to throughout this paper as Type I, II, and III, and they are based on the reference mix designs given in Table 2. The mixes within each group vary in fiber content. The dosages of superplasticizer and limestone filler were slightly adjusted in all cases to maintain a similar workability throughout all mixes (slump values between 10 and $15 \mathrm{~cm}$ ).

32 A highly fractioned factorial plan [25] was followed to define the experimental program.

33 It was organized in three blocks, corresponding to Type I, Type II, and Type III mixes, 
1 resulting in the combinations shown in Table 3 . With this design of the experiment, it

2 was possible to draw reliable, statistically sound conclusions from the experimental 3 results after a reasonable number of tests. For each case, 3 POT specimens and 2

4 cylindrical specimens were produced with concrete from the same batch. The number of 5 POT specimens produced and tested was $9 \times 3=27$ for each of the three series, and 6 therefore the total number of POT specimens was $27 \times 3=81$.

8 Rebars of four different diameters were used: 8, 12, 16, and $20 \mathrm{~mm}$. The different 9 values considered for concrete cover, $\mathrm{C} 1<\mathrm{C} 2<\mathrm{C} 3$, were defined as a function of the 10 rebar diameter. The minimum concrete cover, $\mathrm{C} 1$, was either $30 \mathrm{~mm}$ (type I mixes) or 112.5 times the rebar diameter (types II and III mixes). The maximum concrete cover 12 considered, C3, was set at 5 times the rebar diameter, in agreement with the definition 13 of good confinement by the Model Code [4]. An intermediate level, C2 being the 14 average of $\mathrm{C} 1$ and $\mathrm{C} 3$, was also considered.

16 Four types of hooked-end steel fibers were considered, different in slenderness and length only: 45/50,65/60,80/35, and 80/50. They were dosed below $1 \%$ in volume, considering the following fiber contents: $0 \mathrm{~kg} / \mathrm{m}^{3}, 40 \mathrm{~kg} / \mathrm{m}^{3}$, and $60-70 \mathrm{~kg} / \mathrm{m}^{3}$.

\subsection{Pull Out Test}

22 A modified version of the Pull Out Test (POT) was selected as the most appropriate test 23 for the purposes of this research (Figure 2). All POT specimens were designed to the RILEM recommendations [32-34] prescribing the following requirements: a) the total length of the specimen (L) had to be 10 times the rebar diameter but never less than 200 $\mathrm{mm}$, and b) the embedded length ( $\left.\mathrm{L}^{\prime}\right)$ had to be 5 times the rebar diameter. Preliminary calculations following Eurocode 2 part 1-1 (art. 8.4.2) [26] were made in order to avoid rebar yielding so that specimens failure could be related only to bond failure in all cases.

30 The dimensions of the cross-section were different for each POT specimen. This is sketched in Figure 3, where D is the rebar diameter, $\mathrm{S}$ is the side, and $\mathrm{C}$ is the concrete cover, variable. As shown in Figure 3, the rebar was positioned eccentrically so that the factor 'concrete cover' was restricted to two out of four semi-axes in the cross-section. 
1 With respect to the other two semi-axes, concrete cover was never less than $125 \mathrm{~mm}$ in

2 order to have good confinement.

3

$4 \quad 3.3$ Materials and methods

5

6 Cement type CEM II/B-M 42.5 R was used in all cases. River sand and crushed

7 limestone coarse aggregate were used, in addition to limestone filler and a

8 polycarboxylate ether-based superplasticizer. The reinforcing bars were ribbed bars

9 made with steel type B $500 \mathrm{~S}$. With respect to the steel fibers used, all of them were

10 cold-drawn, hooked-end fibers made with low carbon steel (yield strength $1100 \mathrm{MPa}$

11 minimum) and without any coating.

13 To produce the concrete mixes and cast the specimens, the same sequence of operations

14 and mixing regime was followed in all cases. Each one of the concrete batches was

15 characterized by testing 2 cylindrical specimens under uniaxial compression. These

16 control specimens were cast at the same time as their corresponding POT specimens,

17 kept in storage conditions to the standard EN 12390-2:2009 [27] and tested at the same

18 age as their corresponding POT specimens, 28 days, following the standard EN 12390-

$193: 2009[28]$.

21 Pull out tests were carried out as shown in Figure 4. The specimen was placed on a rigid 22 steel plate with the rebar passing through a hole and anchored by clamps. The supporting plate was pulled up by actuating an hydraulic system and, as a result, the rebar was pulled out of the specimen. The specimen was instrumented with a LVDT sensor on the top surface to monitor the slip of the rebar. It was located on this surface in order to detect the load corresponding to the onset of bond stress along the entire

27 embedded length.

\subsection{Bond capacity parameters}

A bond stress-slip curve was obtained from each Pull Out Test, from which the following parameters were defined as the experimental quantitative outputs to be analyzed in this research (see Figure 5): 
- $\tau_{\max }$, bond strength, corresponding to the peak bond stress, measured in MPa.

- $A_{\text {peak }}$, area under the bond stress-slip curve up to its peak, measured in mmMPa.

- $A_{80}$, area under the bond stress-slip curve up to the bond stress value that equals $80 \%$ of the bond strength in the postpeak region of the curve, measured in mmMPa.

- $A_{50}$, area under the bond stress-slip curve up to the bond stress value that equals $50 \%$ of the bond strength in the postpeak region of the curve, measured in mmMPa.

\section{RESULTS}

\subsection{Concrete compressive strength}

The average compressive strength values obtained for type I, type II, and type III mixes were $32 \mathrm{MPa}, 48 \mathrm{MPa}$, and $44 \mathrm{MPa}$ respectively, at the age of 28 days. The standard deviation observed in the results was $2.7 \mathrm{MPa}, 5.1 \mathrm{MPa}$, and 4.8 $\mathrm{MPa}$ respectively. These values were considered in the analysis of the results presented in following sections.

\subsection{Bond strength and toughness parameters}

Tables 4, 5 and 6 present the experimental results: bond strength values, $\tau_{\max }$, and the toughness parameters $A_{\text {peak, }} \mathrm{A}_{80}$, and $\mathrm{A}_{50}$. These parameters can only be obtained in a consistent manner when the mode of bond failure is pullout, as they are not defined if there is a splitting failure. Therefore the analysis and discussion of results presented in the following section refers to pullout failures only. A detailed analysis of the splitting failures has been already published by the authors [7]. 


\section{5. ANALYSIS AND DISCUSSION}

\subsection{Overview of the methodology}

4

5 The effects of the variables considered $\left(\mathrm{f}_{\mathrm{c}}, \mathrm{D}, \mathrm{C}, \mathrm{C}_{\mathrm{f}}, \lambda_{\mathrm{f}}, \mathrm{l}_{\mathrm{f}}\right)$ on the bond capacity 6 parameters analyzed were evaluated and modelled by means of multiple linear 7 regression [29]. In addition to the equations obtained, statistical significance tests were 8 used to assess the relative importance of each variable. The modelling process followed 9 an iterative construction based on backwards stepwise regression [30] taking as 10 reference this general expression:

$$
z=\nabla_{0}+\nabla_{c} f_{c}+\nabla_{c c} f_{c}^{2}+\nabla_{d} \mathrm{D}+\nabla_{d d} \mathrm{D}^{2}+\nabla_{c d} \frac{C}{D}+C_{f}\left(\nabla_{f}+\nabla_{\lambda f} \lambda_{f}+\nabla_{\ell f} \ell_{f}\right)
$$

13 Where $\mathrm{z}$ is the parameter analyzed ( $\tau_{\max }, \mathrm{A}_{\text {peak }}, \mathrm{A}_{80}$, or $\left.\mathrm{A}_{50}\right)$, and $\nabla_{0}, \nabla_{c}, \nabla_{c c}, \nabla_{d}, \nabla_{d d}$,

$14 \nabla_{c d}, \nabla_{f}, \nabla_{\lambda f}$ and $\nabla_{\ell f}$ are coefficients to be estimated by least squares fitting to the experimental results.

The structure of this general equation was decided taking into account previous knowledge on bond phenomena. It takes into account the contributions of concrete quality (compressive strength), the rebar diameter, and confinement (cover/diameter ratio and fibers). The effects of concrete compressive strength and rebar diameter were modelled as the addition of two components (linear and quadratic) to be able to model non-linear trends if they were found to be statistically significant. The two sources of passive confinement considered in this research are the cover/diameter ratio (C/D) and the fiber content. The contribution of fibers is assumed to be directly dependent on fiber content $\left(C_{f}\right)$ and modified by a fiber geometry factor $\nabla_{F}=\nabla_{f}+\nabla_{\lambda f} \lambda_{f}+\nabla_{\ell f} \ell_{f}$ which takes into account the interactions between $C_{f}$ and fiber slenderness $\left(\lambda_{f}\right)$ and length $\left(\ell_{f}\right)$. 


\section{$1 \quad 5.2$ Bond strength}

2

3 After fitting equation (1) to the experimental results obtained for bond strength $\left(\tau_{\max }\right.$,

4 in $\mathrm{MPa}$ ) and removing the terms that were not statistically significant, the following 5 model was obtained (R-squared=0.78):

$$
\tau_{\max }=70.07-4.43 f_{c}+0.068 f_{c}^{2}+0.026 \mathrm{D}^{2}+1.03 \frac{C}{D}+\nabla_{F} C_{f}
$$

6

7 Where $\nabla_{F}$ is the fiber geometry factor, as follows:

$$
\nabla_{F}=0.51-0.0024 \lambda_{f}-0.0054 \ell_{f}
$$

9 The goodness-of-fit of the model given by equations (2) and (3) was relatively good, 10 with an R-squared of 0.78 . This is illustrated in Figure 6, which shows the relationship 11 between experimental bond strength values and the predictions following these 12 equations, together with the exact equivalence line and the limits of the $95 \%$-confidence 13 band.

15 Figure 7 presents the effects plots for bond strength with respect to the different variables. Solid lines show the average trends and the 95\%-confidence limits for these estimates are represented by grey bands. The relative importance of the different variables on bond strength was assessed through these plots.

Concrete compressive strength was identified as the most determining factor on bond strength, which is consistent with previous literature on the subject [16,31-33]. In bond failures without splitting, the critical process is the crushing of concrete wedges between ribs due to multiaxial compression. This explains why concrete compressive strength was the determining factor in terms of bond strength. On the other hand, the slightly positive effect of fiber reinforcement and concrete cover on bond strength was attributed to their effect at the material level (enhancement of the concrete strength under compression) rather than at a structural level.

Higher rebar diameters yielded higher bond strength values. This cannot be interpreted 
1 bigger ribs and therefore cause higher bond stresses in the rebar-concrete interface to

2 balance the axial load pulling the rebar out of the concrete.

3

4 The improvement of passive confinement, by either increasing the cover/diameter ratio

5 or fiber content, tended to increase the bond strength but only slightly. This was

6 attributed to the fact that, when the bond strength is reached, the microcracking is not

7 yet so advanced as to activate the sewing effect of fibers or the confinement given by

8 the concrete cover.

9

10 Variations in fiber slenderness and length were detected to modify the effect that 11 increasing the fiber content has on bond strength. This is represented by the fiber 12 geometry factor $\nabla_{F}$ given by equation (3). Figure 8 represents the variation of this factor 13 with fiber slenderness and length, and Figure 9 shows the relationship between bond 14 strength and fiber content for different values of fiber length and slenderness. It was 15 observed that, for the same fiber content, shorter fibers were preferable in terms of their 16 impact on bond strength. This was attributed to the fact that the contribution of longer 17 fibers is not fully activated until the microcracking surrounding the rebar is more developed than it is when bond strength is reached. With respect to the slenderness, its effect is related to the section of the fibers.

\subsection{Toughness until the peak, $A_{\text {peak }}$}

23 For the toughness parameter $A_{\text {peak}}$, representing bond toughness in the prepeak region, the following model was obtained $(\mathrm{R}$-squared $=0.45)$ :

$$
\ln \left(A_{\text {peak }}\right)=-0.0762+0.000734 f_{c}^{2}+0.00275 D^{2}+0.167 \frac{C}{D}+0.00856 C_{f}
$$

27 The values of areas under the bond stress-slip curve showed a considerable scatter. This 28 is observed in Figure 10, which shows that higher $A_{\text {peak }}$ values are more scattered: the 29 solid line is the exact equivalence line, while the dashed lines represent the limits of the $3095 \%$-confidence band. Due to the highly scattered profile of $A_{\text {peak }}$ values, predictions 31 obtained by using equation (4) would be associated with a considerable margin of error. 32 However, as a result of the logarithmic transformation applied, it is a reliable tool to 
1 calculate average estimates and therefore for the detection of trends with respect to the

2 different variables considered.

3

4 Concrete compressive strength, rebar diameter, cover/diameter ratio and fiber content

5 were detected to significantly affect $A_{\text {peak }}$ values, and the effects plots showing the

6 average trends in these relationships are presented in Figure 11. 7

8 Increasing concrete compressive strength or considering higher rebar diameters lead to

9 higher toughness, and for the same reasons that have been discussed in relation to their 10 effects on bond strength. Equation (4) can be used to quantify an average value of these 11 relative increments: $A_{\text {peak }}$ is increased by $73 \%$ if concrete compressive strength 12 increases from $32 \mathrm{MPa}$ to $48 \mathrm{MPa}$, and it is increased by $117 \%$ if the rebar diameter is $1320 \mathrm{~mm}$ instead of $8 \mathrm{~mm}$.

15 The effects of fiber length and slenderness on $A_{\text {peak }}$ values were not statistically 16 significant and that is the reason why they do not appear in equation (4). Therefore the 17 effect of fibers on $A_{\text {peak }}$ depends only on the fiber content and is not affected by fiber slenderness or length as long as they fall within the ranges considered in this research. In average, $A_{\text {peak }}$ is increased by $71 \%$ when $70 \mathrm{~kg} / \mathrm{m}^{3}$ of fibers are used, with respect to 20 the situation with no fibers.

\subsection{Post-peak toughness, $A_{80}$ and $A_{50}$}

The following equations were obtained for the postpeak toughness parameters $A_{80}(R-$ squared $=0.57)$ and $\mathrm{A}_{50}(\mathrm{R}$-squared $=0.59)$ :

$$
\ln \left(A_{80}\right)=0.204+0.000975 f_{c}^{2}+0.00318 \mathrm{D}^{2}+0.235 \frac{C}{D}+0.00962 C_{f}
$$

$$
\ln \left(A_{50}\right)=0.717+0.00108 f_{c}^{2}+0.00325 D^{2}+0.214 \frac{C}{D}+0.0095 C_{f}
$$

28 Both equations are discussed together as they have the same structure and yield very 29 similar information. Figure 12 shows the effects plots for $\mathrm{A}_{80}$, and the trends observed in 30 these plots are the same as in the case of $\mathrm{A}_{50}$. 
2 Consistently with the findings in relation to $A_{\text {peak, }}$ geometrical differences between the

3 fibers considered in this research did not have a statistically significant effect on post-

4 peak bond toughness, and the effect of fibers on either $\mathrm{A}_{80}$ or A50 was related to fiber

5 content only. It is quite interesting to note that the addition of $70 \mathrm{~kg} / \mathrm{m}^{3}$ of fibers had the

6 same relative impact on both parameters ( $\mathrm{A}_{80}$ is increased by $82 \%$ while $\mathrm{A}_{50}$ is increased

7 by $81 \%$, in average, with respect to concrete without fibers), which was quite similar to

8 that observed for $A_{\text {peak }}$ (relative increase of $71 \%$ ).

9

10 In fact, the same applies to the other variables considered. If the rebar diameter is 11 increased from $8 \mathrm{~mm}$ to $20 \mathrm{~mm}, \mathrm{~A}_{80}$ is increased by $142 \%$ while $\mathrm{A}_{50}$ is increased by $12148 \%$, in average. For a concrete compressive strength value of $48 \mathrm{MPa}, \mathrm{A}_{80}$ is 13 increased by $123 \%$ and $\mathrm{A}_{50}$ is increased by $151 \%$ with respect to a compressive strength 14 value of $32 \mathrm{MPa}$. And when $\mathrm{C} / \mathrm{D}$ ratio is set at 5.0 instead of 2.5, A80 is increased by $1560 \%$ and $\mathrm{A}_{50}$ is increased by $52 \%$.

17 From all the aforementioned similarities, it can be concluded that the trends observed with respect to the different variables analyzed are very similar for $\mathrm{A}_{80}$ and $\mathrm{A}_{50}$. This suggests that the definition of a bond toughness parameter extended to the post-peak region as an area under the bond stress-slip curve allows some flexibility regarding its explicit definition.

23 Important similarities are also found in relation to the scatter of these parameters, and the same considerations made with respect to $A_{\text {peak }}$ are applicable to both $A_{80}$ and $A_{50}$. The scatter pattern observed in all these parameters is quite consistent: the higher their average value is, the more scattered they are. Furthermore, as can be observed in Figure 13 , it is also remarkable that there is a strong linear correlation between any of these areas and bond strength (R-squared between 0.52 and 0.68 ).

\section{CONCLUSIONS}

33 The experimental results obtained from a series of pull out tests have been used to analyze the effect of a number of factors (concrete compressive strength, rebar diameter, 
1 concrete cover, fibers content, and fibers length and slenderness) on bond strength and

2 toughness. The semi-empirical expressions obtained for these parameters provide estimates of the relative importance of the different factors considered.

4

The following conclusions are obtained, based on the results of these investigations:

- Concrete compressive strength was identified as the most determining factor on bond strength, which is consistent with previous literature on the subject.

- Higher rebar diameters yielded higher bond strength values as larger rebar diameters have bigger ribs which increase wedging action.

- The effect of fiber content on bond strength is of limited importance. The passive confinement exerted by either increasing the concrete cover or fiber content, tended to increase the bond strength but only slightly, as the microcracking was not yet so advanced at the peak bond stress.

- Variations in fiber slenderness and length were detected to modify the effect that increasing the fiber content has on bond strength. The most remarkable effect observed was than, for a same fiber content, shorter fibers resulted more effective than longer fibers to improve bond strength.

- Concrete compressive strength, rebar diameter, cover/diameter ratio and fiber content were detected to significantly affect toughness until the peak $\left(\mathrm{A}_{\text {peak }}\right)$.

- The effects of the studied factors on the post-peak toughness were the same regardeless the level the bond stress level ( $\mathrm{A}_{80}$ or $\left.\mathrm{A}_{50}\right)$.

- The effect of fibers on bond toughness parameters ( $A_{\text {peak, }}, A_{80}$ and $A_{50}$ ) is much more noticeable than on bond strength. Their contribution to bond toughness depends only on the fiber content and is not affected by fiber slenderness or length as long as they fall within the ranges considered in this research.

- Finally, with regard to the relationship between bond strength and toughness parameters, it has been detected that there is a strong linear correlation between bond strength and all the areas considered ( $\mathrm{A}_{\text {peak }}, \mathrm{A}_{80}$ and $\left.\mathrm{A}_{50}\right)$ as well as with the scatter of their values.

\section{ACKNOWLEDGEMENTS}


1 The authors of this work wish to thank both the Research Bureau of the Spanish

2 Ministry of Science and Innovation for the funding of the projects 'BIA 2009-12722'

3 and 'BIA 2012-35776-AR', this research being a part thereof.

4 
2

3 8

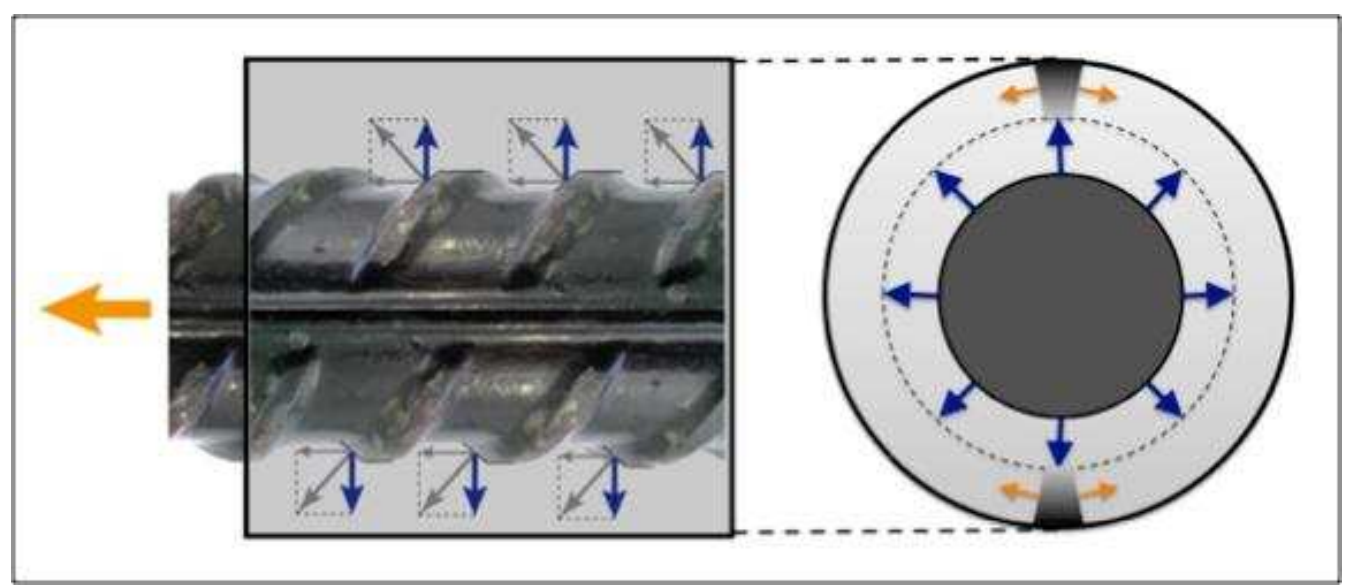

Figure 1. Bond stresses and radial stresses generated at the rebar-concrete interface.

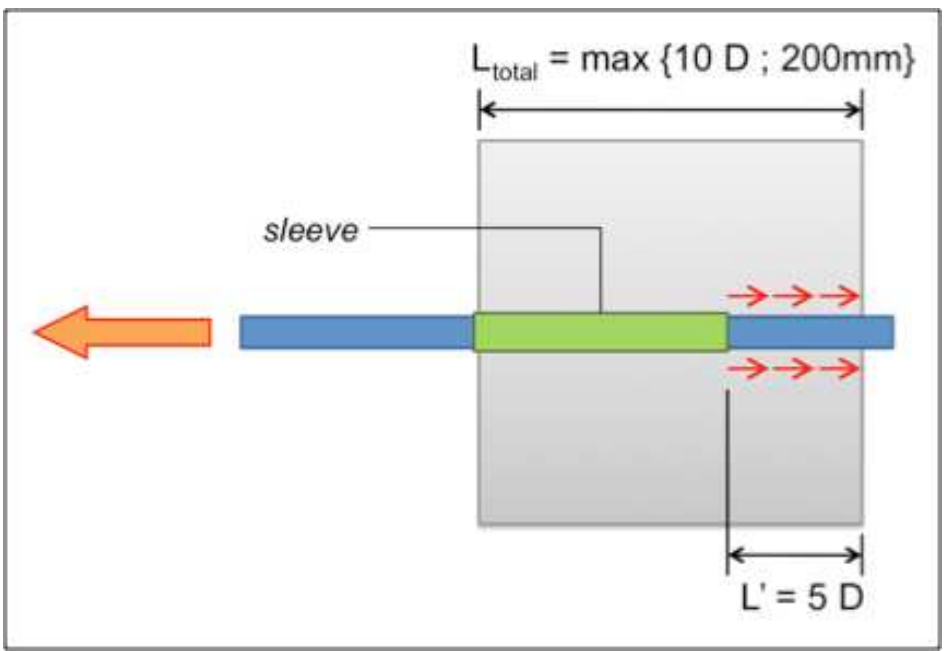

Figure 2. Longitudinal view of POT specimen according to RILEM recommendations.

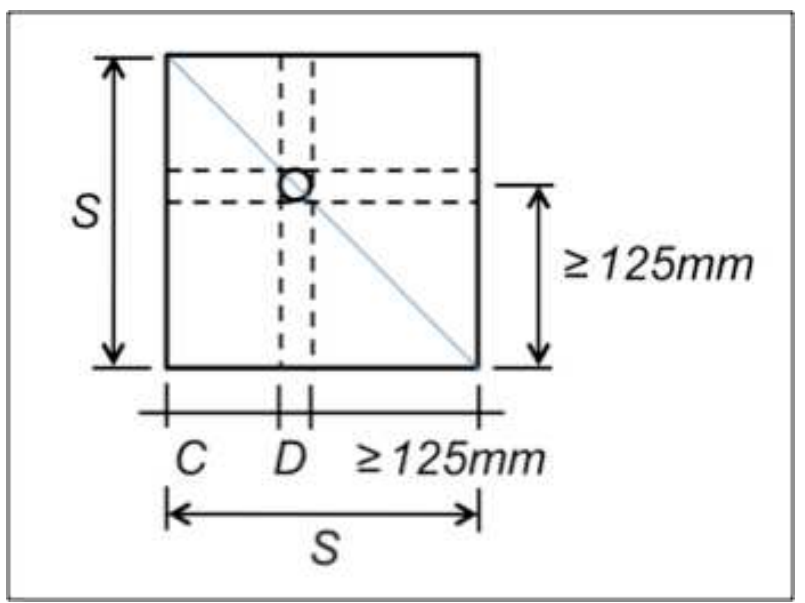

Figure 3. Cross-section of POT specimens. 

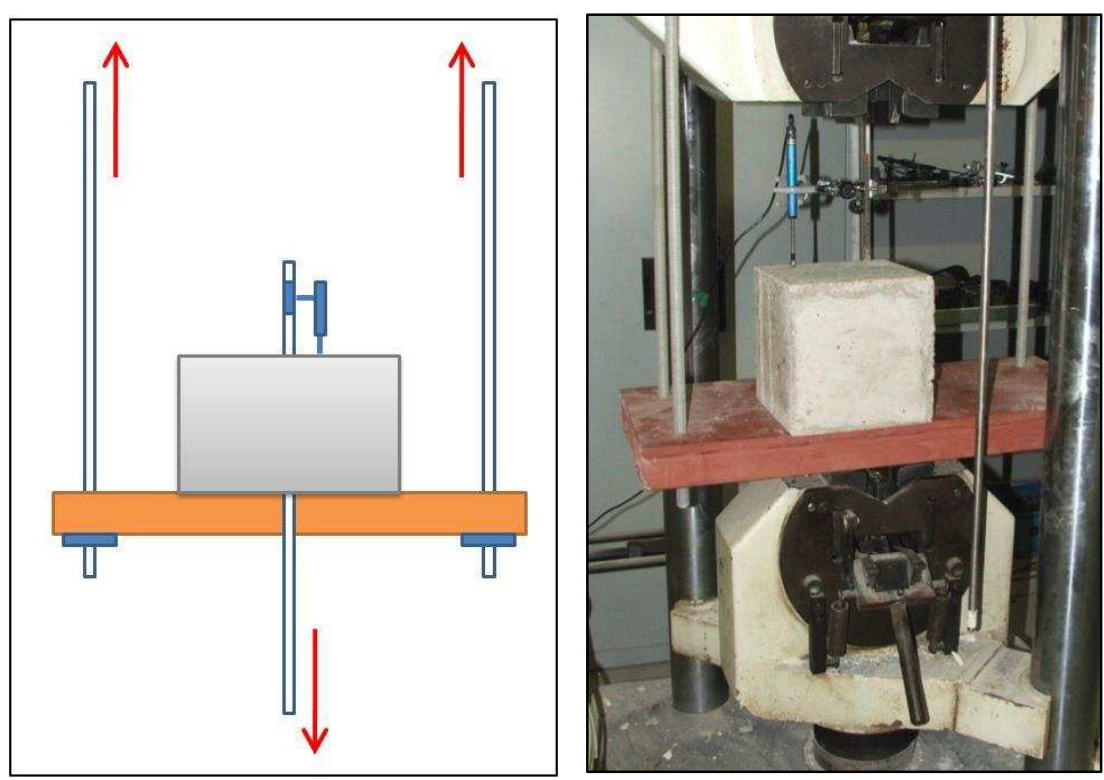

Figure 4. Force diagram (left) and picture of the Pull Out Test (right).

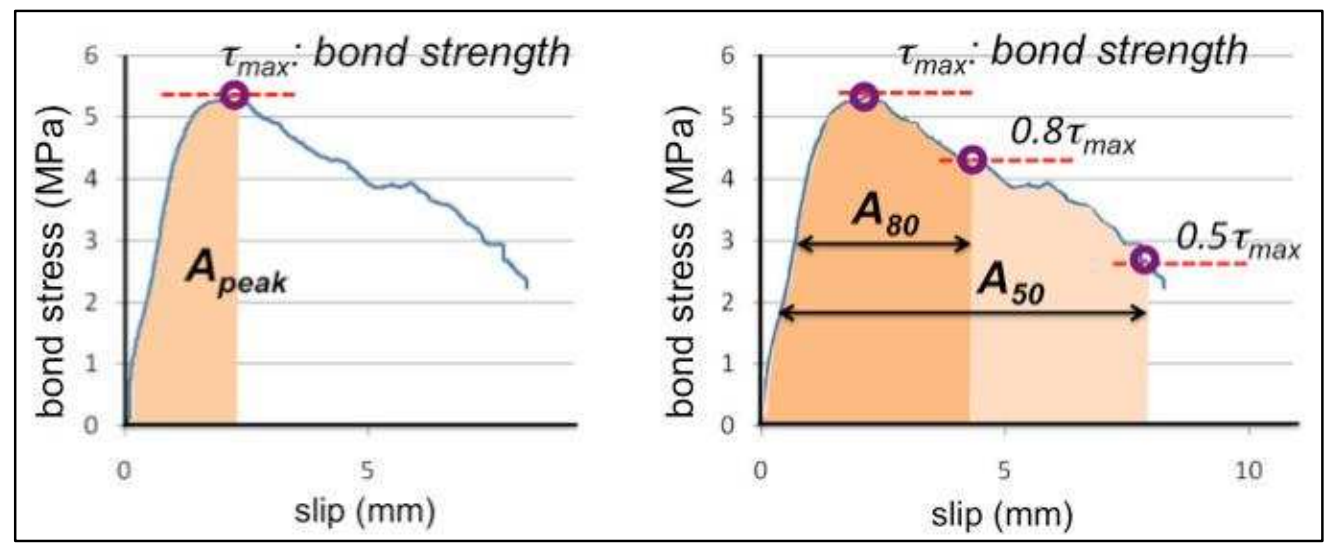

Figure 5. Definition of toughness parameters.

6

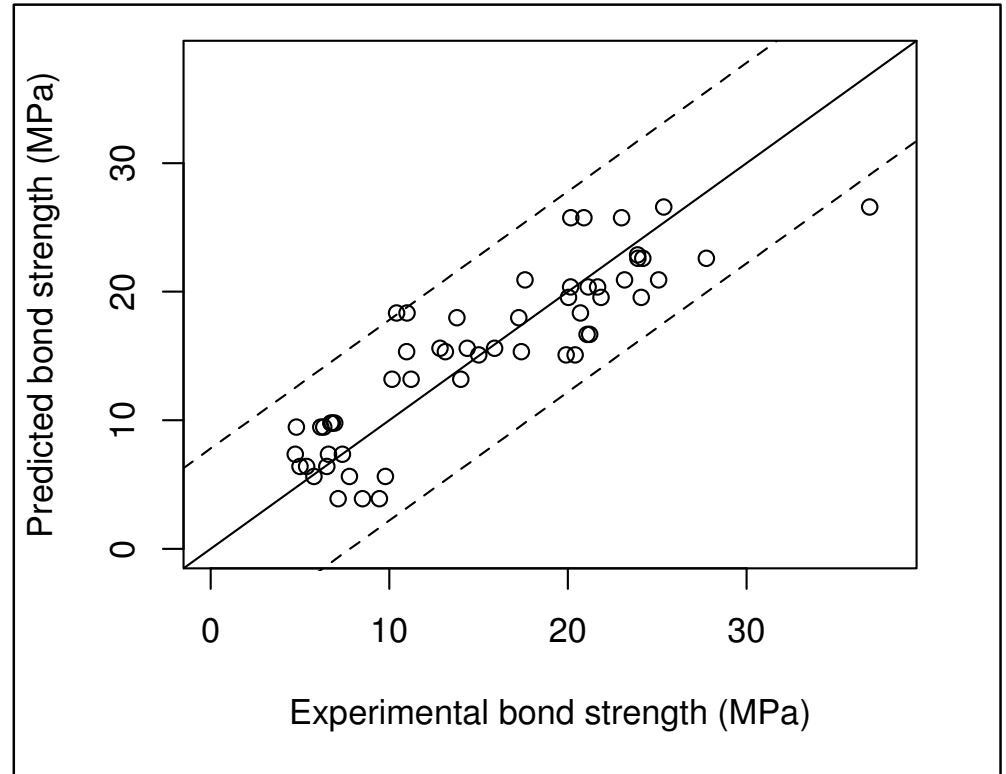

Figure 6. Predicted vs experimental values of bond strength. 

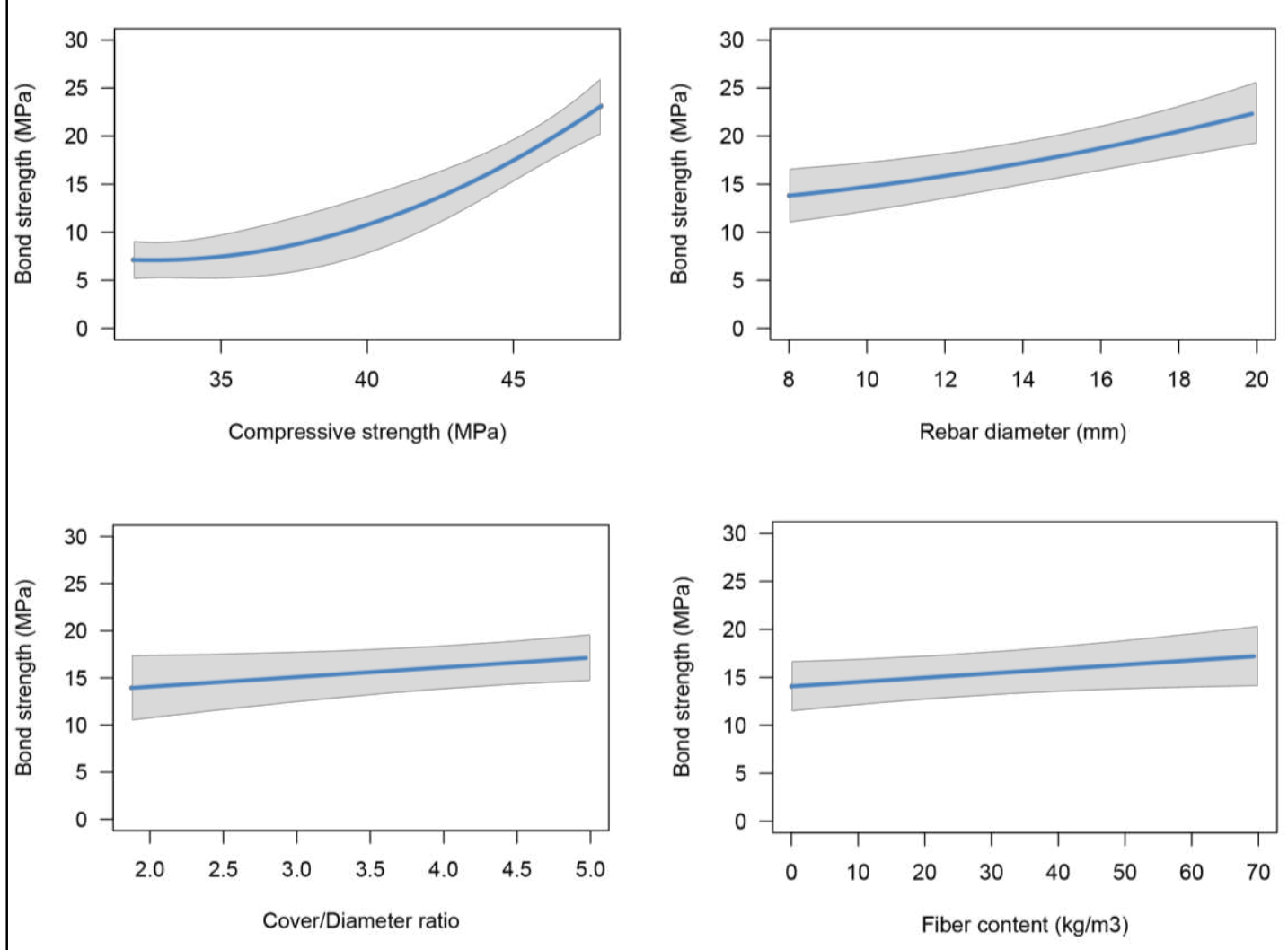

Figure 7. Bond strength: average trends with respect to the factors considered.

4

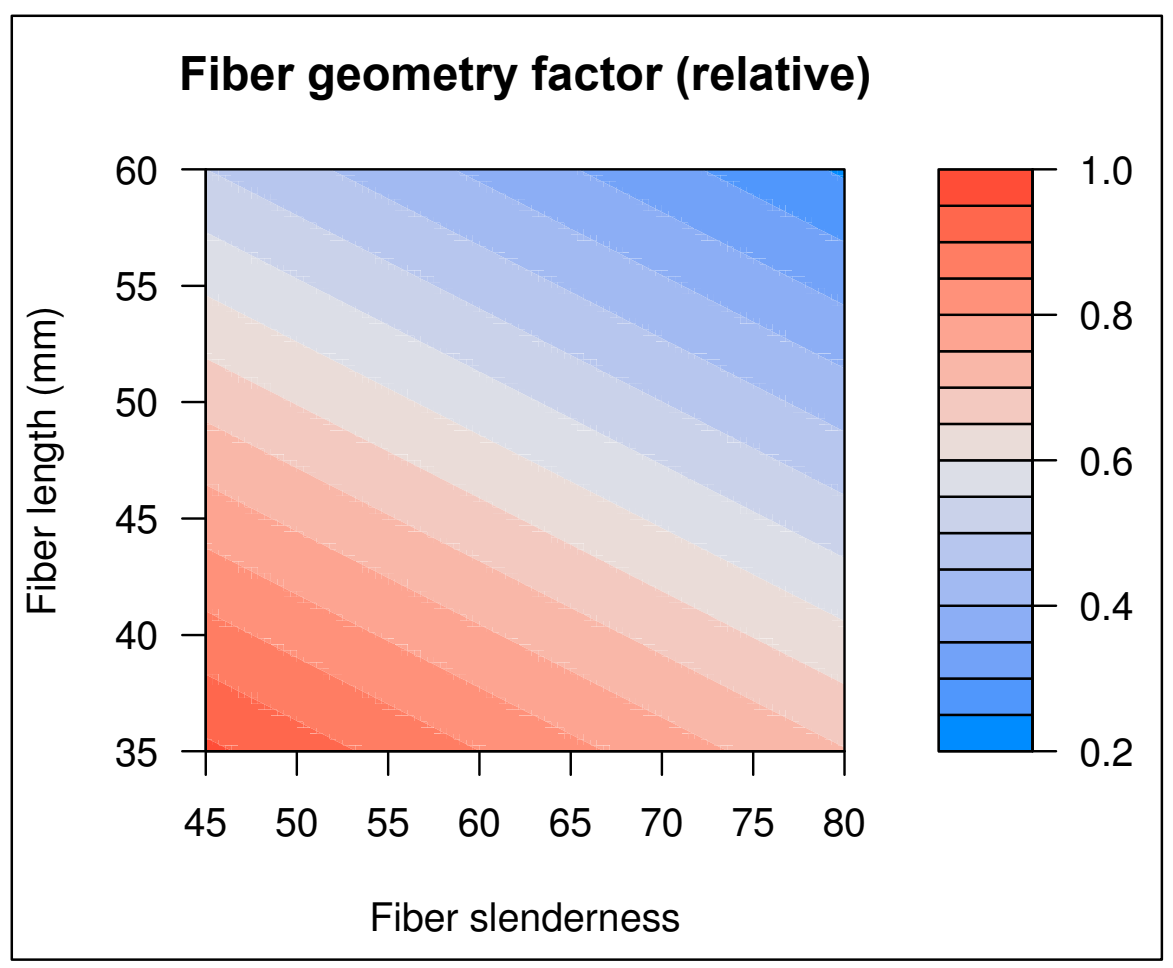

6 Figure 8. Bond strength: relative value of the fiber geometry function $\left(\nabla_{F} / \nabla_{F, \text { max }}\right)$. 


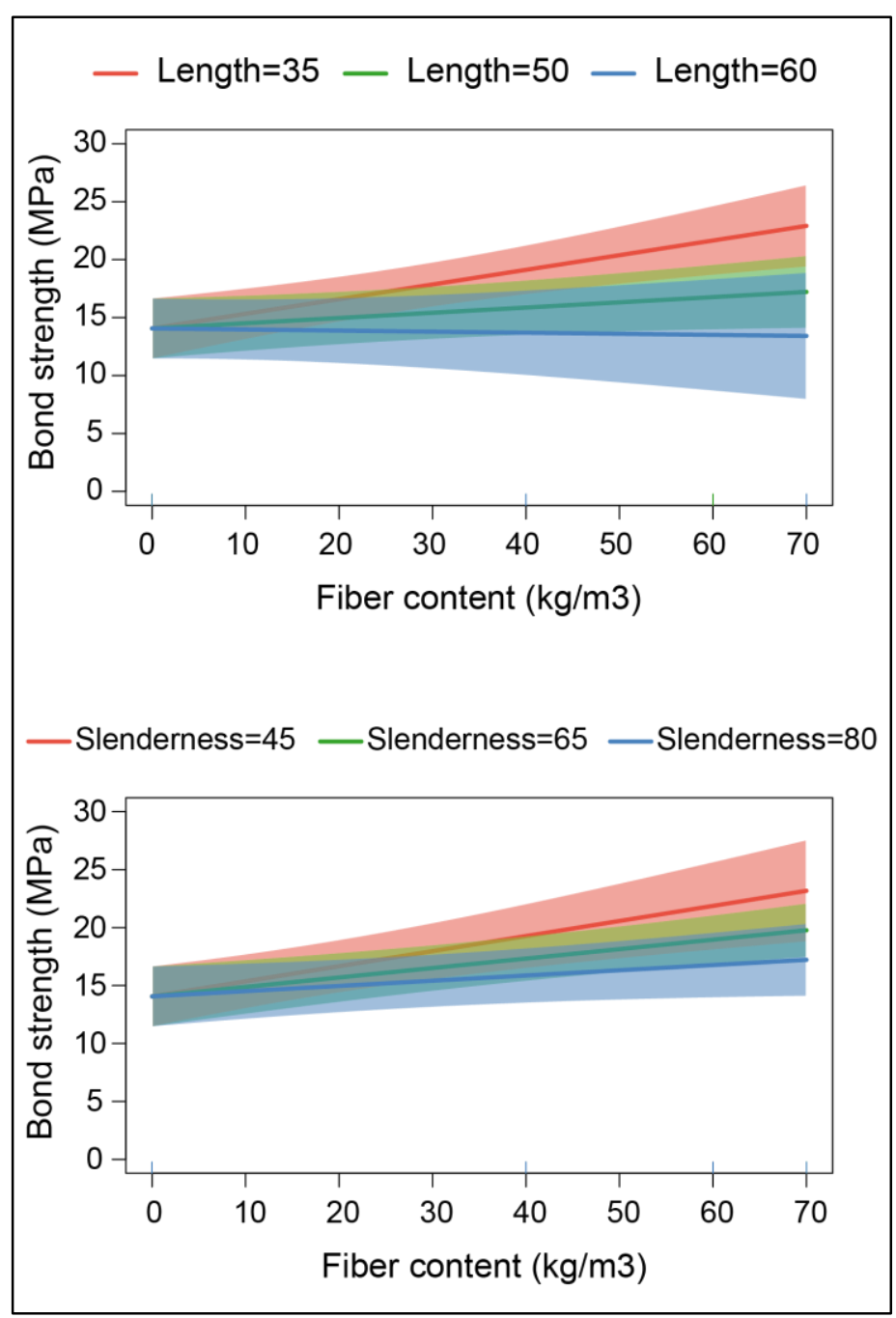

Figure 9. Effect of fiber length (a) and slenderness (b) on bond strength.

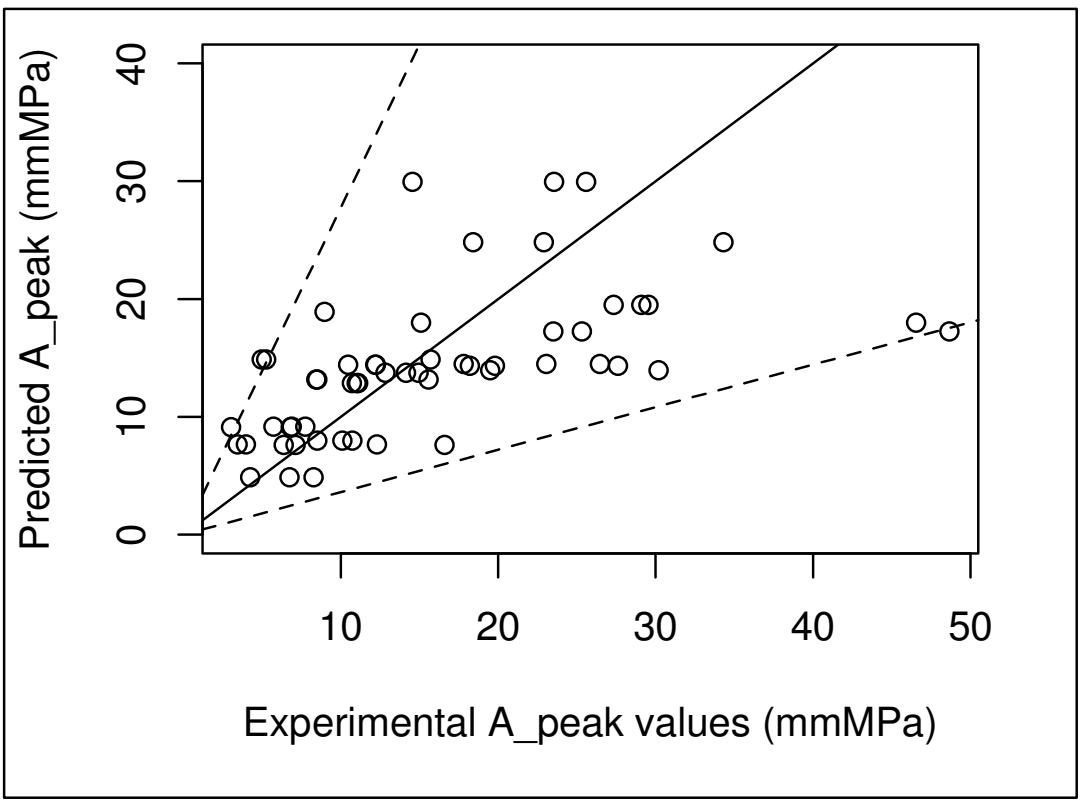

Figure 10. Predicted vs experimental values of toughness parameter $A_{\text {peak. }}$. 

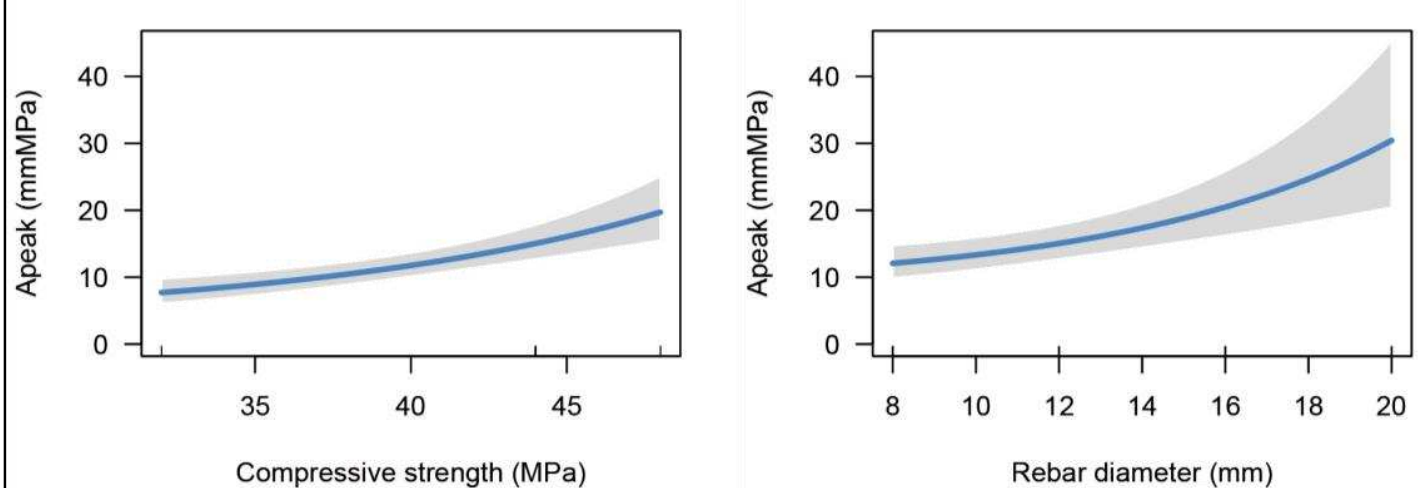

Compressive strength (MPa)
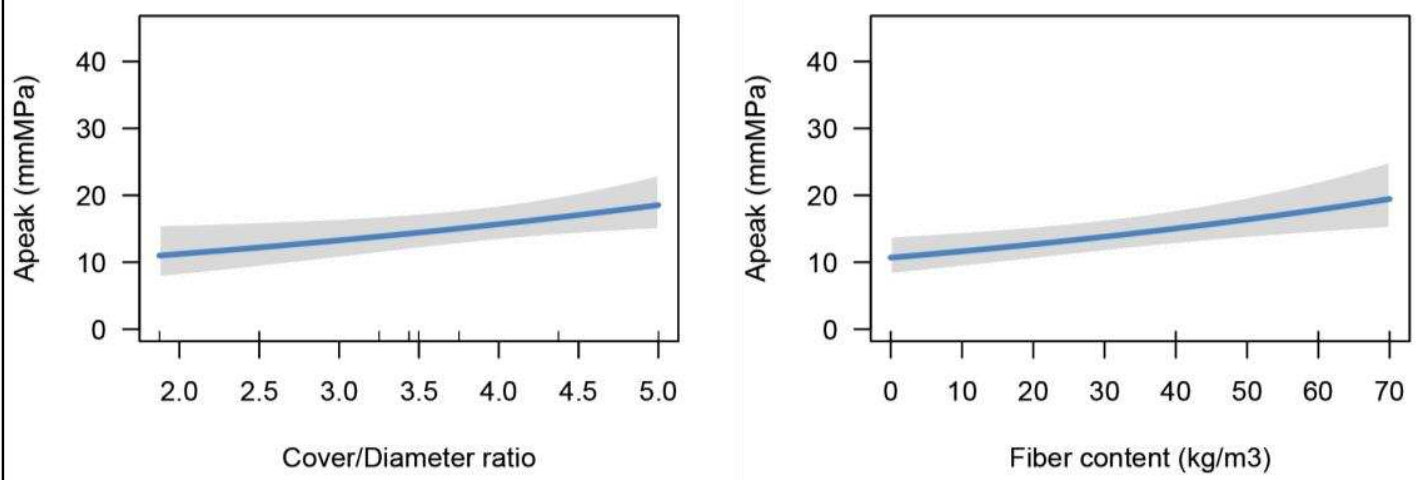

Figure 11. Toughness, Apeak: average trends with respect to the factors considered.
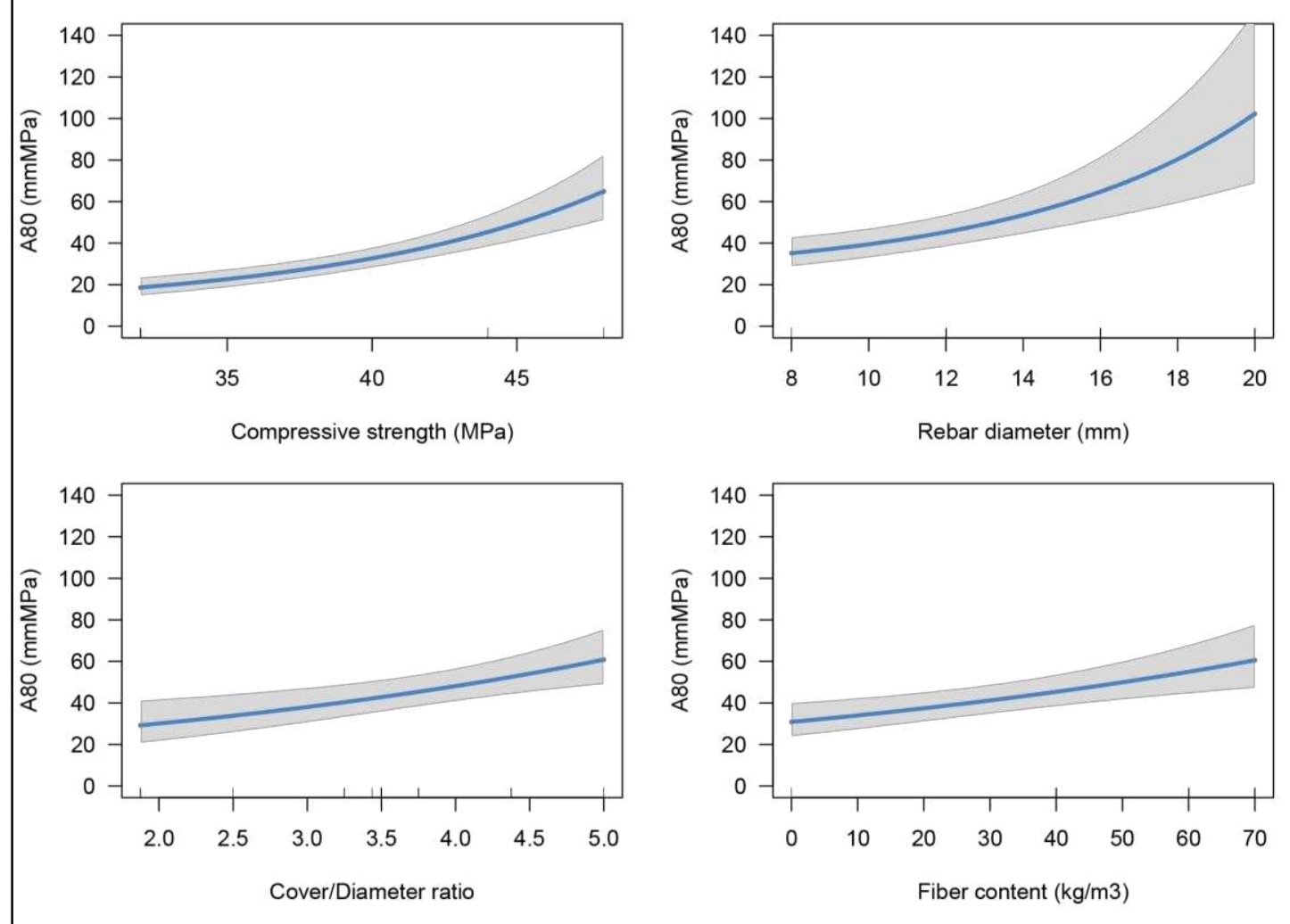

Figure 12. Toughness, $\mathrm{A}_{80}$ : average trends with respect to the factors considered. 


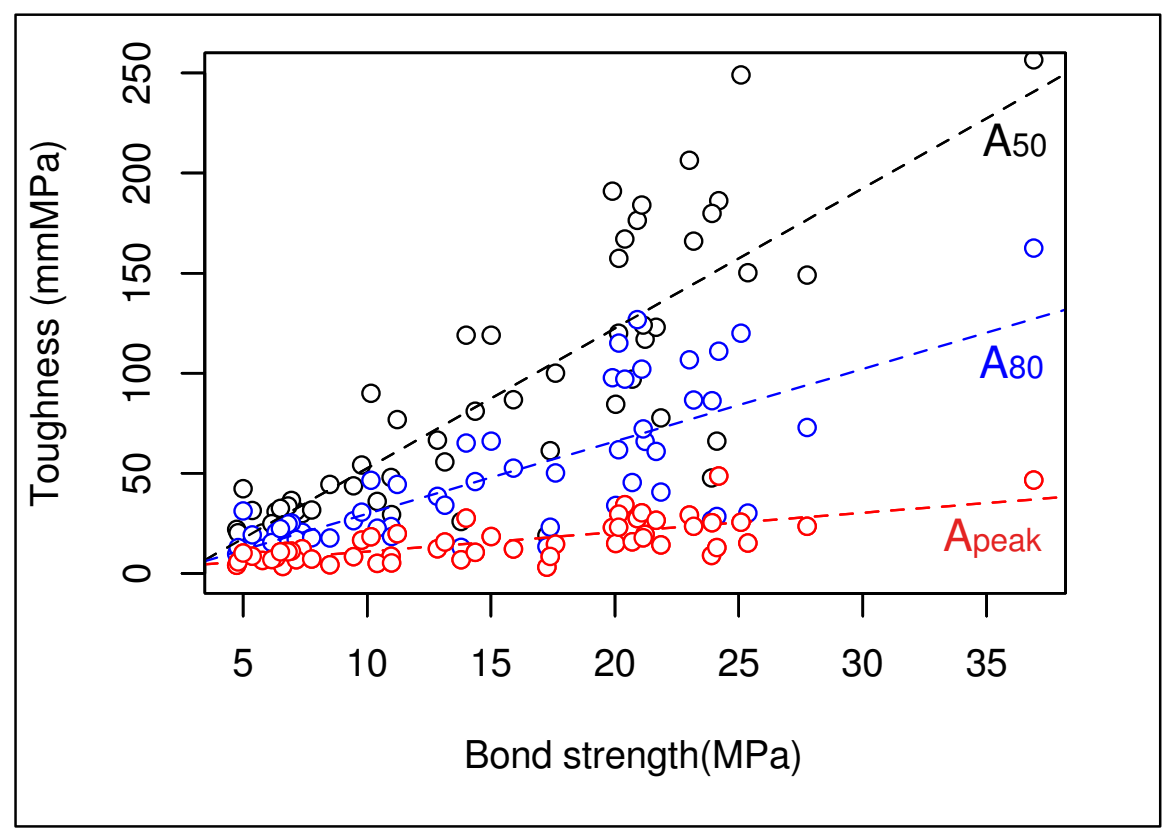

2 Figure 13. Relationship between the toughness parameters and bond strength. 
2

Table 1. Factors and levels considered.

\begin{tabular}{|c|c|c|c|}
\hline Factor & Type I mixes & $\begin{array}{c}\text { Type II } \\
\text { mixes }\end{array}$ & $\begin{array}{c}\text { Type III } \\
\text { mixes }\end{array}$ \\
\hline \multirow{3}{*}{ Rebar diameter, mm } & 8 & 8 & 8 \\
& 16 & 12 & 12 \\
& 20 & 16 & 16 \\
\hline \multirow{2}{*}{ Concrete cover } & $\mathrm{C} 1=30 \mathrm{~mm}$ & $\mathrm{C} 1=2.5 \mathrm{D}$ & $\mathrm{C} 1=2.5 \mathrm{D}$ \\
& $\mathrm{C} 2=(\mathrm{C} 1+\mathrm{C} 3) / 2$ & $\mathrm{C} 2=3.5 \mathrm{D}$ & $\mathrm{C} 2=3.5 \mathrm{D}$ \\
& $65 / 60$ & $\mathrm{C} 3=5.0 \mathrm{D}$ & $\mathrm{C} 3=5.0 \mathrm{D}$ \\
\hline Fiber geometry & $80 / 50$ & $45 / 50$ & $45 / 50$ \\
(slenderness $/$ length, & & $80 / 50$ & $80 / 50$ \\
mm $/ \mathrm{mm})$ & 0 & 0 & $80 / 35$ \\
\hline & 40 & 40 & 0 \\
Fiber content, $\mathrm{kg} / \mathrm{m}^{3}$ & 70 & 60 & 60 \\
\hline
\end{tabular}

4

Table 2. Reference mix designs $\left(\mathrm{kg} / \mathrm{m}^{3}\right)$.

\begin{tabular}{|l|c|c|c|}
\hline & Type I & Type II & Type III \\
\hline Water/Cement & 0.60 & 0.45 & 0.55 \\
\hline Cement & 325 & 440 & 325 \\
\hline Sand 0/4 & 1006 & 957 & 1050 \\
\hline Coarse aggr. 7/12 & 544 & 723 & 835 \\
\hline Coarse aggr. 12/20 & 362 & - & - \\
\hline Filler & - & 72 & 37 \\
\hline Superplasticizer & 1.40 & 10 & 1.40 \\
\hline
\end{tabular}

6 
Table 3. Combinations tested.

\begin{tabular}{|c|c|c|c|c|}
\hline Mix id. & $\begin{array}{c}\text { Fibers } \\
\text { geometry } \\
\left(\lambda_{f} / l_{f}\right)\end{array}$ & $\begin{array}{c}\text { Fiber } \\
\text { content } \\
\left(\mathrm{kg} / \mathrm{m}^{3}\right)\end{array}$ & $\begin{array}{l}\text { Rebar } \\
\text { diameter } \\
(\mathrm{mm})\end{array}$ & $\begin{array}{c}\text { Concrete } \\
\text { Cover }\end{array}$ \\
\hline I-1 & $65 / 60$ & 40 & 16 & C1 \\
\hline $\mathrm{I}-2$ & - & 0 & 8 & $\mathrm{C} 2$ \\
\hline $\mathrm{I}-3$ & $65 / 60$ & 70 & 20 & $\mathrm{C} 3$ \\
\hline $\mathrm{I}-4$ & $65 / 60$ & 40 & 8 & $\mathrm{C} 3$ \\
\hline $\mathrm{I}-5$ & - & 0 & 20 & $\mathrm{C} 1$ \\
\hline I-6 & $65 / 60$ & 70 & 16 & $\mathrm{C} 2$ \\
\hline I-7 & $80 / 50$ & 40 & 20 & $\mathrm{C} 2$ \\
\hline I-8 & - & 0 & 16 & C3 \\
\hline I-9 & $80 / 50$ & 70 & 8 & $\mathrm{C} 1$ \\
\hline II-1 & - & 0 & 8 & $\mathrm{C} 1$ \\
\hline II-2 & $80 / 35$ & 60 & 8 & $\mathrm{C} 2$ \\
\hline II-3 & $45 / 50$ & 40 & 8 & $\mathrm{C} 3$ \\
\hline II-4 & $45 / 50$ & 60 & 12 & $\mathrm{C} 1$ \\
\hline II-5 & $80 / 50$ & 40 & 12 & $\mathrm{C} 2$ \\
\hline II-6 & - & 0 & 12 & $\mathrm{C} 3$ \\
\hline II-7 & $80 / 35$ & 40 & 16 & $\mathrm{C} 1$ \\
\hline II-8 & - & 0 & 16 & $\mathrm{C} 2$ \\
\hline II-9 & $80 / 50$ & 60 & 16 & $\mathrm{C} 3$ \\
\hline III-1 & - & 0 & 8 & $\mathrm{C} 1$ \\
\hline III-2 & $80 / 50$ & 40 & 12 & $\mathrm{C} 2$ \\
\hline III-3 & $80 / 50$ & 60 & 16 & $\mathrm{C} 3$ \\
\hline III-4 & - & 0 & 12 & $\mathrm{C} 3$ \\
\hline III-5 & $45 / 50$ & 40 & 16 & $\mathrm{C} 1$ \\
\hline III-6 & $45 / 50$ & 60 & 8 & $\mathrm{C} 2$ \\
\hline III-7 & - & 0 & 16 & $\mathrm{C} 2$ \\
\hline III-8 & $80 / 35$ & 40 & 8 & $\mathrm{C} 3$ \\
\hline III-9 & $80 / 35$ & 60 & 12 & $\mathrm{C} 1$ \\
\hline
\end{tabular}


Table 4. Experimental results, POT specimens made with Type I mixes.

\begin{tabular}{|c|c|c|c|c|}
\hline \multirow[t]{2}{*}{ Mix id. } & \multirow{2}{*}{$\begin{array}{l}\text { Bond strength } \\
(\mathrm{MPa})\end{array}$} & \multicolumn{3}{|c|}{ Toughness (mmMPa) } \\
\hline & & $A_{\text {peak }}$ & $A_{80}$ & $A_{50}$ \\
\hline \multirow{3}{*}{$\mathrm{I}-1$} & 4.74 & 3.97 & 9.58 & 21.90 \\
\hline & 6.60 & 3.45 & 9.64 & 24.40 \\
\hline & 7.38 & 12.30 & 20.50 & 29.80 \\
\hline \multirow{3}{*}{$\mathrm{I}-2$} & 9.45 & 8.27 & 26.30 & 43.70 \\
\hline & 7.14 & 6.75 & 16.90 & 31.20 \\
\hline & 8.50 & 4.24 & 17.60 & 44.40 \\
\hline \multirow{3}{*}{$\mathrm{I}-3$} & 19.90 & 22.90 & 97.70 & 191.00 \\
\hline & 15.01 & 18.40 & 66.10 & 119.00 \\
\hline & 20.40 & 34.30 & 97.00 & 167.00 \\
\hline \multirow{3}{*}{$\mathrm{I}-4$} & 7.77 & 7.12 & 17.80 & 31.60 \\
\hline & 5.78 & 6.38 & 12.50 & 20.20 \\
\hline & 9.78 & 16.60 & 30.50 & 54.10 \\
\hline \multirow{3}{*}{$\mathrm{I}-5$} & \multicolumn{4}{|c|}{ splitting } \\
\hline & \multicolumn{4}{|c|}{ splitting } \\
\hline & \multicolumn{4}{|c|}{ splitting } \\
\hline \multirow{3}{*}{$\mathrm{I}-6$} & 6.95 & 11.10 & 25.20 & 36.40 \\
\hline & 6.73 & 11.00 & 23.60 & 33.10 \\
\hline & 6.81 & 10.71 & 24.70 & 33.70 \\
\hline \multirow{3}{*}{$\mathrm{I}-7$} & 14.00 & 27.60 & 65.10 & 119.00 \\
\hline & 11.22 & 19.80 & 44.40 & 76.80 \\
\hline & 10.16 & 18.20 & 46.50 & 90.00 \\
\hline \multirow{3}{*}{ I- 8} & 6.33 & 7.75 & 20.50 & 30.85 \\
\hline & 4.80 & 5.72 & 12.90 & 20.30 \\
\hline & 6.16 & 6.88 & 15.40 & 24.80 \\
\hline \multirow{3}{*}{ I-9 } & 5.37 & 8.51 & 19.20 & 31.35 \\
\hline & 6.50 & 10.73 & 22.30 & 32.50 \\
\hline & 5.00 & 10.10 & 31.10 & 42.30 \\
\hline
\end{tabular}

3 
Table 5. Experimental results, POT specimens made with Type II mixes.

\begin{tabular}{|c|c|c|c|c|}
\hline \multirow[t]{2}{*}{ Mix id. } & \multirow{2}{*}{$\begin{array}{l}\text { Bond strength } \\
(\mathrm{MPa})\end{array}$} & \multicolumn{3}{|c|}{ Toughness (mmMPa) } \\
\hline & & $A_{\text {peak }}$ & $A_{80}$ & $A_{50}$ \\
\hline \multirow{3}{*}{ II-1 } & 13.79 & 6.82 & 13.00 & 25.85 \\
\hline & \multicolumn{4}{|c|}{ splitting } \\
\hline & 17.25 & 3.04 & 13.39 & 18.95 \\
\hline \multirow{3}{*}{ II-2 } & 36.89 & 46.54 & 162.46 & 256.54 \\
\hline & 25.36 & 15.09 & 30.06 & 150.22 \\
\hline & \multicolumn{4}{|c|}{ (unavailable-testing failed) } \\
\hline \multirow{3}{*}{ II-3 } & 20.90 & 27.34 & 126.79 & 176.40 \\
\hline & 20.16 & 29.55 & 115.01 & 157.34 \\
\hline & 23.00 & 29.09 & 106.75 & 206.42 \\
\hline \multirow{3}{*}{ II-4 } & \multicolumn{4}{|c|}{ splitting } \\
\hline & \multicolumn{4}{|c|}{ splitting } \\
\hline & \multicolumn{4}{|c|}{ splitting } \\
\hline \multirow{3}{*}{ II-5 } & \multicolumn{4}{|c|}{ splitting } \\
\hline & \multicolumn{4}{|c|}{ splitting } \\
\hline & 23.90 & 8.97 & 26.52 & 47.62 \\
\hline \multirow{3}{*}{ II-6 } & 27.75 & 23.50 & 72.90 & 148.98 \\
\hline & 24.19 & 48.66 & 111.00 & 186.15 \\
\hline & 23.92 & 25.32 & 86.30 & 179.85 \\
\hline \multirow{3}{*}{ II-7 } & \multicolumn{4}{|c|}{ splitting } \\
\hline & \multicolumn{4}{|c|}{ splitting } \\
\hline & \multicolumn{4}{|c|}{ splitting } \\
\hline \multirow{3}{*}{ II -8} & \multicolumn{4}{|c|}{ splitting } \\
\hline & \multicolumn{4}{|c|}{ splitting } \\
\hline & \multicolumn{4}{|c|}{ splitting } \\
\hline \multirow{3}{*}{ II-9 } & \multicolumn{4}{|c|}{ splitting } \\
\hline & \multicolumn{4}{|c|}{ splitting } \\
\hline & \multicolumn{4}{|c|}{ splitting } \\
\hline
\end{tabular}


2 Table 6. Experimental results, POT specimens made with Type III mixes.

\begin{tabular}{|c|c|c|c|c|}
\hline \multirow[t]{2}{*}{ Mix id. } & \multirow{2}{*}{$\begin{array}{l}\text { Bond strength } \\
(\mathrm{MPa})\end{array}$} & \multicolumn{3}{|c|}{ Toughness (mmMPa) } \\
\hline & & $A_{\text {peak }}$ & $A_{80}$ & $A_{50}$ \\
\hline \multirow{3}{*}{ III-1 } & \multicolumn{4}{|c|}{ splitting } \\
\hline & \multicolumn{4}{|c|}{ splitting } \\
\hline & \multicolumn{4}{|c|}{ splitting } \\
\hline \multirow{3}{*}{ III-2 } & 15.90 & 12.19 & 52.60 & 86.70 \\
\hline & 12.84 & 12.23 & 38.50 & 66.50 \\
\hline & 14.36 & 10.47 & 45.80 & 81.00 \\
\hline \multirow{3}{*}{ III-3 } & 23.17 & 23.54 & 86.60 & 166.00 \\
\hline & 25.08 & 25.58 & 120.00 & 249.00 \\
\hline & 17.60 & 14.55 & 50.10 & 100.00 \\
\hline \multirow{3}{*}{ III-4 } & 10.97 & 8.51 & 23.40 & 47.90 \\
\hline & 13.14 & 15.58 & 34.00 & 55.60 \\
\hline & 17.39 & 8.45 & 23.00 & 61.30 \\
\hline \multirow{3}{*}{ III-5 } & \multicolumn{4}{|c|}{ splitting } \\
\hline & \multicolumn{4}{|c|}{ splitting } \\
\hline & \multicolumn{4}{|c|}{ splitting } \\
\hline \multirow{3}{*}{ III-6 } & 21.85 & 14.15 & 40.60 & 77.70 \\
\hline & 20.03 & 14.94 & 33.90 & 84.50 \\
\hline & 24.11 & 12.84 & 28.40 & 66.10 \\
\hline \multirow{3}{*}{ III-7 } & 21.22 & 19.49 & 65.90 & 117.00 \\
\hline & \multicolumn{4}{|c|}{ splitting } \\
\hline & 21.08 & 30.18 & 102.00 & 184.00 \\
\hline \multirow{3}{*}{ III-8 } & 10.41 & 4.97 & 22.50 & 35.90 \\
\hline & 10.99 & 5.27 & 18.40 & 29.40 \\
\hline & 20.70 & 15.70 & 45.40 & 97.00 \\
\hline \multirow{3}{*}{ III-9 } & 20.15 & 23.05 & 61.70 & 120.00 \\
\hline & 21.66 & 26.46 & 60.90 & 123.00 \\
\hline & 21.14 & 17.81 & 72.20 & 124.00 \\
\hline
\end{tabular}

3

4 


\section{REFERENCES}

3 [1] Cairns J, Plizzari GA. Towards a harmonised European bond test. Materials and Structures 2003;36:498-506. doi:10.1007/BF02480826.

[2] Bamonte PF, Gambarova PG. High-Bond Bars in NSC and HPC: Study on Size Effect and on the Local Bond Stress-Slip Law. Journal of Structural Engineering 2007;133:225. doi:10.1061/(ASCE)0733-9445(2007)133:2(225).

[3] Gambarova PG. Bond in reinforced concrete: where do we stand today?, Brescia, Italy: 2012, pp. 1-13.

[4] fib. fib Model Code for Concrete Structures 2010. Weinheim, Germany: WileyVCH Verlag GmbH \& Co. KGaA; 2013. doi:10.1002/9783433604090. Cairns J, Jones K. The splitting forces generated by bond. Magazine of Concrete Research 1995;47:153-65. doi:10.1680/macr.1995.47.171.153.

[6] ACI American Concrete Institute. Building Code Requirements for Structural

[7] García-Taengua E, Martí-Vargas JR, Serna P. Splitting of concrete cover in steel fiber reinforced concrete: Semi-empirical modeling and minimum confinement requirements. Construction and Building Materials 2014;66:74351. doi:10.1016/j.conbuildmat.2014.06.020.

[8] Yalciner H, Eren O, Sensoy S. An experimental study on the bond strength between reinforcement bars and concrete as a function of concrete cover, strength and corrosion level. Cement and Concrete Research 2012;42:643-55. doi:10.1016/j.cemconres.2012.01.003.

[9] Arel HS, Yazici S. Concrete-reinforcement bond in different concrete classes. Construction and Building Materials 2012;36:78-83. doi:10.1016/j.conbuildmat.2012.04.074.

[10] García-Taengua E, Martí-Vargas JR, Serna-Ros P. Statistical Approach to Effect of Factors Involved in Bond Performance of Steel Fiber-Reinforced Concrete. ACI Structural Journal 2011;108:461-8.

[11] Serna P, Arango S, Ribeiro T, Núñez A, García-Taengua E. Structural cast-inplace SFRC: technology, control criteria and recent applications in spain. Materials and Structures 2009;42:1233-46. doi:10.1617/s11527-009-9540-9.

[12] Shah AA, Ribakov Y. Recent trends in steel fibered high-strength concrete. Materials \& Design 2011;32:4122-51. doi:10.1016/j.matdes.2011.03.030.

[13] Cairns J, Plizzari GA. Bond behaviour of conventional reinforcement in fibre reinforced concrete, Varenna, Italy: 2004.

Holschemacher K, Weisse D. Bond of reinforcement in fibre reinforced concrete, Varenna, Italy: 2004. fiber reinforced concrete in the cracked state. Construction and Building Materials 2014;65:321-9. doi:10.1016/j.conbuildmat.2014.04.139.
Dancygier AN, Katz A, Wexler U. Bond between deformed reinforcement and 
normal and high-strength concrete with and without fibers. Materials and Structures 2010;43:839-56. doi:10.1617/s11527-009-9551-6.

[17] Darwin D, Zuo J. Development Length Criteria for Conventional and High Relative Rib Area Reinforcing Bars. ACI Structural Journal 1996;93:347-59.

[18] Lundgren K, Gylltoft K. A Model for the Bond between Concrete and Reinforcement. Magazine of Concrete Research 2000;52:53-63.

[19] Harajli MH, Mabsout ME. Evaluation of Bond Strength of Steel Reinforcing Bars in Plain and Fiber-Reinforced Concrete. ACI Structural Journal 2002;99:509-17.

[20] Russo G, Pauletta M. A simple method for evaluating the maximum slip of anchorages. Materials and Structures 2006;39:533-46. doi:10.1617/s11527006-9092-1.

[21] Russo G, Pauletta M, Mitri D. Solution for bond distribution in asymmetric R.C. structural members. Engineering Structures 2009;31:633-41. doi:10.1016/j.engstruct.2008.11.003.

[22] Tastani SP, Pantazopoulou SJ. Direct Tension Pullout Bond Test: Experimental Results. Journal of Structural Engineering 2010;136:731-43. doi:10.1061/(ASCE)ST.1943-541X.0000159.

[23] Harajli MH. Bond Stress-Slip Model for Steel Bars in Unconfined or Steel, FRC, or FRP Confined Concrete under Cyclic Loading. Journal of Structural Engineering 2009;135:509-18. doi:10.1061/(ASCE)07339445(2009)135:5(509).

[24] Cattaneo S, Rosati G. Bond between Steel and Self-Consolidating Concrete: Experiments and Modeling. ACI Structural Journal 2009;106:540-50.

[25] Montgomery D. Design and Analysis of Experiments. 6 ed. New York: John Wiley \& Sons Inc; 2005.

[26] European Committee for Standardization. EN 1992-1-1:2004 Eurocode 2 Design of concrete structures, Part 1-1: General rules and rules for buildings. 2004.

[27] European Committee for Standardization. EN 12390-2: 2009 Testing hardened concrete - Part 2: Making and curing specimens for strength tests. 2009. doi: $10.3403 / 30164912$.

[28] European Committee for Standardization. EN 12390-3:2009 Testing hardened concrete - Part 3: Compressive strength of test specimens. 2009.

[29] Hair J, Black W, Babin B, Anderson R. Multivariate Data Analysis. 7 ed. Upper Saddle River, NJ: Prentice Hall; 2009.

[30] Taengua EG. Bond of Reinforcing Bars to Steel Fiber Reinforced Concrete (SFRC). 2013.

[31] Chapman RA, Shah SP. Early-age Bond Strength in Reinforced Concrete. ACI Materials Journal 1987;84:501-10.

[32] Hughes BP, Videla C. Design criteria for early-age bond strength in reinforced concrete. Materials and Structures 1992;25:445-63. doi:10.1007/BF02472635.

[33] Harajli MH. Comparison of Bond Strength of Steel Bars in Normal- and HighStrength Concrete. J Mat in Civ Engrg 2004;16:365-74. 
doi:10.1061/(ASCE)0899-1561(2004)16:4(365).

2 